\title{
Seasonal analysis of cloud characteristics and radiative effect over the Iberian Peninsula using MODIS-CERES observations
}

\author{
M. D. Freile-Aranda ${ }^{1}$, J. L. Gómez-Amo ${ }^{1}$, M. P. Utrillas ${ }^{1}$, R. Pedros ${ }^{1}$ and J. A. Martínez-Lozano ${ }^{1}$ \\ ${ }^{1}$ Solar Radiation Group, Earth Physics and Thermodynamics Department, University of Valencia \\ Received: 24/X/2016 - Accepted: 31/I/2017 - Original version
}

Correspondence to: jmartine@uv.es

\begin{abstract}
We studied the seasonal evolution of clouds in four climatic regions within the Iberian Peninsula during the 2000-2012 period by using satellite data from CERES and MODIS instruments. We analysed cloud cover, cloud optical thickness, cloud-top temperature, and long-and shortwave radiative effect on top of the atmosphere for these four climatic regions. Cloud cover is larger in the north (regions 1 and 4) than in the south (regions 2 and 3) and shows a seasonal behaviour with summer minima for all regions. The maximum cover is found in region 1, with a mean yearly value of $61 \%$. Region 3 shows the minimum cloud cover with an annual average around 43\%. Cloud optical thickness ranges between 10 and 22 for low clouds, and between 8 and 20 for high clouds. Moreover, cloud-top temperature for low clouds is 265-285 $\mathrm{K}$ and in the range of 240-269 K for high clouds. Shortwave radiative effect is negative and ranging between -50 and $-150 \mathrm{Wm}^{-2}$ for low clouds and from -50 to $-175 \mathrm{Wm}^{-2}$ for high clouds. Longwave radiative effect is positive and in the range of 5-20 Wm $\mathrm{Wm}^{-2}$ for low clouds and around $75 \mathrm{Wm}^{-2}$ for high clouds. Generally, the longwave effect is lower than that for shortwave resulting in a net radiative effect of between $40 \mathrm{Wm}^{-2}$ and $-150 \mathrm{Wm}^{-2}$ for low clouds and in the range of $10-90 \mathrm{Wm}^{-2}$ for high clouds.
\end{abstract}

Key words: cloud optical thickness, cloud cover, radiative effect, CERES, MODIS

\section{Introduction}

Clouds have a great impact on the Earth's climate. Besides their critical implications in the Earth's water cycle (Lin et al., 2000), clouds are the main parameter affecting the energy balance in the Earth-atmosphere system at regional and planetary scales, which is decisive for climate studies (Nakajima and King, 1990). Clouds strongly modulate the Radiation Budget by absorbing and scattering solar and thermal radiation (Cess et al., 1989; Roebeling et al., 2013). In particular, clouds play a key role in the solar radiation reaching the Earth's surface, generally reducing it (by up to nearly $80 \%$ ) depending mainly on the cloud type, its optical thickness and distribution in the sky (Calbó et al., 2005). In addition, clouds greatly change in structure and composition at different temporal and spatial scales and represent one of the largest sources of uncertainty in predicting climate at regional and planetary scales (e.g. Solomon et al., 2007; Dong et al., 2008). The greatest contribution of these uncertainties comes from the cloud-radiation interactions (Xu et al., 2005).

Usually, the radiative effects of clouds are quantified in terms of cloud-radiative effect (CRE), which is defined as the difference in the net flux between overcast and clear sky conditions in the tropopause (Ramanathan et al., 1989; Chylek and Wong, 1998). Generally, the cloud effects on climate are antagonistic in two spectral ranges: cooling when speaking in terms of solar spectrum (shortwave) and warming for thermal (longwave) radiation (Chen et al., 2000). Chen et al. (2000) estimated the global annual average of the shortwave CRE to be $-50 \mathrm{Wm}^{-2}$, and $+20 \mathrm{Wm}^{-2}$ for the longwave. This negative $30 \mathrm{Wm}^{-2}$ imbalance indicates a net cooling effect for the whole Earth-atmosphere system. However, this result does not hold 
for all cloud types, seasons and regions.

The magnitude effect depends on the type of cloud and its optical and microphysical properties (Chen et al., 2000; Roebeling et al., 2013; McCoy et al., 2014). The macrophysical properties are their spatial distribution and vertical extent, which are characterized by cloud amount, height and geometrical thickness. On the other hand, the microphysical parameters are the particle size and shape in the cloud, cloud thermodynamic phase and cloud water/ice content (e.g. Dong et al., 2008; Roebeling et al., 2013). The number of water drops (or ice crystals) per volume unit and their size distribution determine the extinction cross-section of the cloud. The integration of such coefficient over cloud height yields the cloud optical thickness (COT) linking the macro- and microphysical properties. Cloud cover and COT are the most relevant quantities to describe cloud radiative effects (Min et al., 2012). Continuous measurements of these properties, their global distribution, and their seasonal and interannual variations are essential for a better understanding of the role of clouds in weather and climate (Roebeling et al., 2013).

Despite the key role of clouds in the Earth's balance, they are probably one of the meteorological phenomena that are least studied from a climatic point of view (Calbó and Sabburg, 2008; Sanchez-Lorenzo et al., 2012). Cloud climatology has been developed from two kinds of data: (1) using radiances measured by satellites in polar and geostationary orbits; and (2) using visual observations of clouds from the Earth's surface, as coded in weather reports from stations on land and ships in the ocean. Satellites detect clouds principally at visible and thermal infrared wavelengths. The cloud-top altitude is inferred by relating the infrared emission temperature to the vertical profile of temperature obtained from radiosondes (carried by weather balloons) or satellite sounders (Warren and Hahn, 2003). Ground-based visual observation of cloud cover is a standard procedure carried out in meteorological observatories. Until the end of the last century, cloud cover estimates from the ground were carried out mainly by human observers. Nowadays, instruments and algorithms for cloud detection and separation between clear sky and cloudy conditions have been further improved to reduce uncertainties in deriving cloud cover and distribution. Several authors introduced various "all sky cameras" (Oznovitch et al., 1994; Shields et al., 1998; Long et al., 2001; Morris, 2004; Calbó and Sabburg, 2008), pyranometers (Long and Ackermann, 2000, Long et al., 2006), pyrgeometers (Durr and Philipona, 2004. Ruffieux et al., 2006, Morland and Mätzler, 2007) and ceilometers (Ahrens 2009; Boers et al., 2010: Martucci et al, 2010) to derive cloud conditions and characteristics.

For some years, the precise determination of cloud properties and their radiative effects from satellite data has been a top priority objective in the Atmospheric Physics community, in particular their space and time variations. Satellite data improve the spatial coverage of the cloud measurements and are a powerful tool in cloud analysis from a global perspective. In addition, the exploitation of long-term satellite data may be a significant contribution. The continuous climatological analysis of cloud properties and their radiative effects can enhance the historical series from ground-based stations.

The NASA Clouds and the Earth's Radiant Energy System (CERES) project was designed to improve the understanding of the cloud-radiation interactions and cloud feedbacks on the Earth Radiation Budget (Wieliki et al., 1996). The project provides the first long-term determinations of cloud properties and radiative impact. For this, the cloud properties determined by the ModerateResolution Imaging Spectroradiometer (MODIS) instrument are combined with top of the atmosphere (TOA) radiative fluxes measured by the CERES instrument. In this piece of research, we have used 12-year satellite data of the Iberian Peninsula to assess the seasonal variation of cloud radiative-effect - solar and thermal ranges - on top of the atmosphere. Cloud effects on the surface are not analysed considering that the radiative effects on TOA are more interesting for the study of the role of clouds on the Earth's Radiation Budget. Besides, we have studied cloud cover, optical thickness and cloud-top temperature (CTT). The study area shows a marked geographical variation in cloud cover, with the northern part having higher values as an average (Calbó et al., 2008). This change will influence radiative effect and contribute to the climatic differences in the Peninsula. Therefore, the Iberian Peninsula has been divided into four climatic regions according to the Iberian Climatic Atlas (AEMET, 2011). In addition, we address the effect of high and low clouds separately. The cloud classification suggested by Rossow and Schiffer (1991) has been used to distinguish between low and high clouds. Although middle clouds were initially considered in this classification, they were not finally analysed because there was not enough data meeting the required conditions to representatively address the study of middle clouds (Section 2).

The paper is structured as follows: the instruments, data and methodology are described in Section 2; the results section (Section 3) presents the seasonal analysis for the cloud properties (COT and CTT) and cloud-radiative effect (CRE). Finally, the results are summarised in Section 4.

\section{Data and methodology}

The Moderate-Resolution Imaging Spectroradiometer (MODIS) is on board the Terra and Aqua satellites. MODIS is a 36-band spectroradiometer that provides several cloud properties by using spectral bands from visible to thermal infrared. We use MOD08_D3 product, which includes daily measurements of optical thickness, cloud-top temperature, and effective particle radius (Platnick et al., 2003) gridded at a latitude and longitude resolution of $1^{\circ} \times 1^{\circ}$ (roughly $100 \mathrm{~km} \times 100 \mathrm{~km}$ at mid-latitudes). 
The Clouds and the Earth's Radiant Energy System (CERES) is a radiometer also on board the Terra and Aqua platforms. CERES measures the radiation on top of the atmosphere in three channels: a shortwave channel for the solar reflected radiation in 0.3-5 $\mu \mathrm{m}$; a second channel measures the Earth's surface emitted radiation in the atmospheric window of 8-12 $\mu \mathrm{m}$; and the third channel measures the whole spectrum. The longwave radiation is the result of subtracting the shortwave channel from the whole-spectrum. We use the daily level 3 CERES_SYN1degDay Ed3A product on the long- and shortwave radiative fluxes gridded at a latitude and longitude resolution of $1^{\circ} \times 1^{\circ}$ (Wielicki et al., 1996; Minnis et al., 2011). This product is produced as a combination of Aqua-Terra CERES/MODIS measurements and geostationary satellite measurements. The geostationary satellites used because of the location of the Iberian Peninsula are METEOSAT-7, METEOSAT-8 and METEOSAT-9 (Doelling et al., 2013). In addition, this data product also includes the modelling fluxes of clear sky conditions. The cloud-radiative effect (CRE) on top of the atmosphere is computed by (1),

$$
C R E=\left(-F^{\uparrow}\right)^{\text {cloudy }}-\left(-F^{\uparrow}\right)^{\text {clear }}
$$

where $F^{\uparrow}$ is the upward flux and the superscript cloudy and clear respectively indicate covered and clear sky conditions. In this piece of research, we use a dataset of almost 12 years, spanning from March 2000 to December 2012 in the Iberian Peninsula. The study area has been divided into four climatic regions according to the Köppen-Geiger classification of average temperature and precipitation (AEMET, 2011). We cannot consider all the existing climates in the Peninsula separately, due to the limited spatial resolution of data. Therefore, we have considered four regions, each one representing approximately one climate (see Fig. 1): (1) temperate with hot summer and without dry season; (2) warm steppe; (3) temperate with hot and dry summer; (4) temperate with temperate summer and without dry season.

We had to ensure radiative effect was only due to one type of cloud (either high or low) and not to their combined effect. Thus, we selected only those pixels showing a cloud cover above $80 \%$ for one cloud type and under $20 \%$ for the other. Then, the selected data was averaged for each cloud type, region and season. When there were no pixels that met the required conditions in a given region, that property was not represented.

\section{Results}

We studied the seasonal values of the following quantities: cloud cover; cloud optical thickness (COT); cloud-top temperature (CTT); and cloud-radiative effect on top of the atmosphere for long- $\left(\mathrm{CRE}_{L W}\right)$ and shortwave radiation $\left(\mathrm{CRE}_{S W}\right)$. We analysed the 4 Iberian climatic zones for high and low cloud situations. The results have

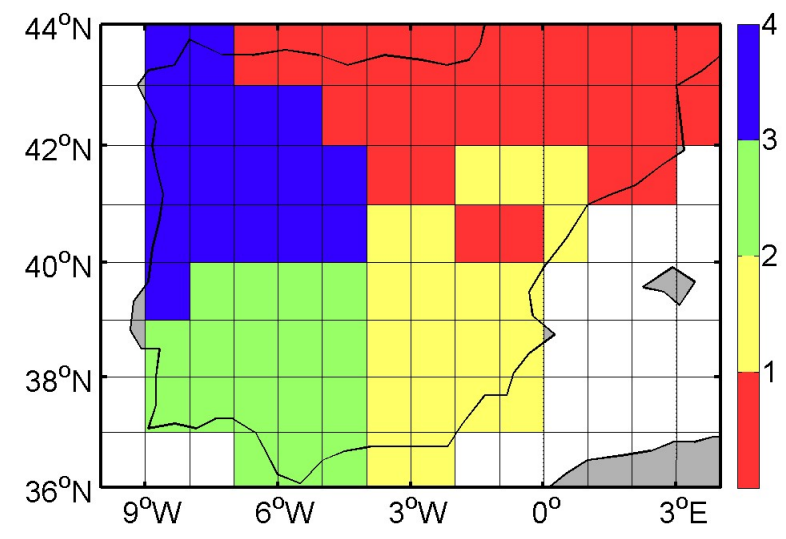

Figure 1. Map of the climatic regions defined in the Iberian Peninsula: 1- temperate with hot summer and without dry season; 2warm steppe; 3- temperate with hot and dry summer; 4- temperate with temperate summer and without dry season.

been arranged in box diagrams with the median (red line), 25 and 75 percentile (blue), and the outliers (red). Outliers are considered to be data higher than $\mathrm{p} 75+1.5(\mathrm{p} 75-\mathrm{p} 25)$ or smaller than $\mathrm{p} 25-1.5(\mathrm{p} 75-\mathrm{p} 25)$. These limits are represented by whiskers (black).

\subsection{Total cloud cover}

There are differences in the total cloud cover among the 4 climatic regions (Table 1). The difference between maximum (region 1) and minimum (region 3 ) is nearly $15 \%$. This difference is larger in summer and may be related to the drier summer in region 3 . On the other hand, regions 2 and 4 have similar intermediate values of cloud cover, although $4 \%$ lower in region 2, especially in winter and autumn (Table 1). In addition, a seasonal variation occurs in all the four regions, both in the average and in the number of days above the $80 \%$ threshold. This is because the climate of the Iberian Peninsula strongly depends on the Azores anticyclone (Lyamani et al., 2015). The minimum cloud cover appears in summer, since the Azores anticyclone sends air masses coming from the Caribbean over the Iberian Peninsula (Martínez-Lozano et al., 2011) leading to dry and mild weather. On the other hand, autumn and winter have unstable, wet and windy weather. The Azores anticyclone causes low pressure systems passing over the Iberian Peninsula, resulting in the prevalence of westerly winds and enhanced rainfall (Lyamani et al., 2015). Consequently, cloud cover increases in winter and autumn (Table 1). Region 1 presents the highest annual cloud cover and the highest seasonal values. On the other hand, region 3 always has the lowest values of total cloud cover. These results 
Table 1. Seasonal and annual average (and standard deviation) of cloud cover for the climatic regions in the Iberian Peninsula and for the whole Peninsula.

\begin{tabular}{cccccc}
\hline SEASON ( $\mathrm{n}^{\circ}$ of pixels with cloud cover above $\left.80 \%\right)$ & 1 & 2 & 3 & 4 & IP \\
\hline WINTER $(25.5 \%)$ & $64(30)$ & $52(30)$ & $49(30)$ & $59(30)$ & $56(30)$ \\
SPRING $(25.2 \%)$ & $63(30)$ & $52(30)$ & $47(30)$ & $54(30)$ & $55(30)$ \\
SUMMER $(25.5 \%)$ & $51(30)$ & $39(20)$ & $28(20)$ & $39(20)$ & $40(20)$ \\
AUTUMN $(23.8 \%)$ & $66(20)$ & $53(30)$ & $49(30)$ & $61(30)$ & $58(30)$ \\
ANNUAL & $61(30)$ & $50(30)$ & $44(30)$ & $53(30)$ & $52(30)$ \\
\hline
\end{tabular}

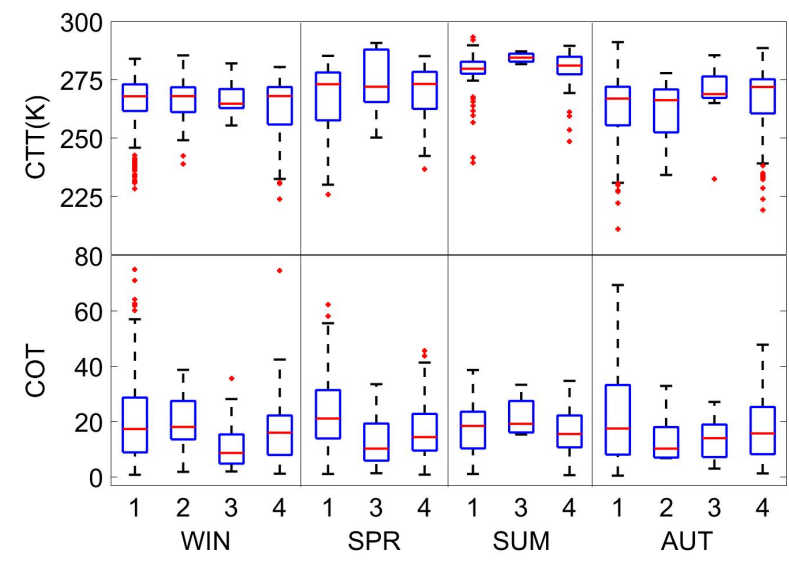

Figure 2. a) Cloud-top temperature $\left(\mathrm{CTT}_{L}\right)$ and; b) cloud optical thickness for low clouds $\left(\mathrm{COT}_{L}\right)$.

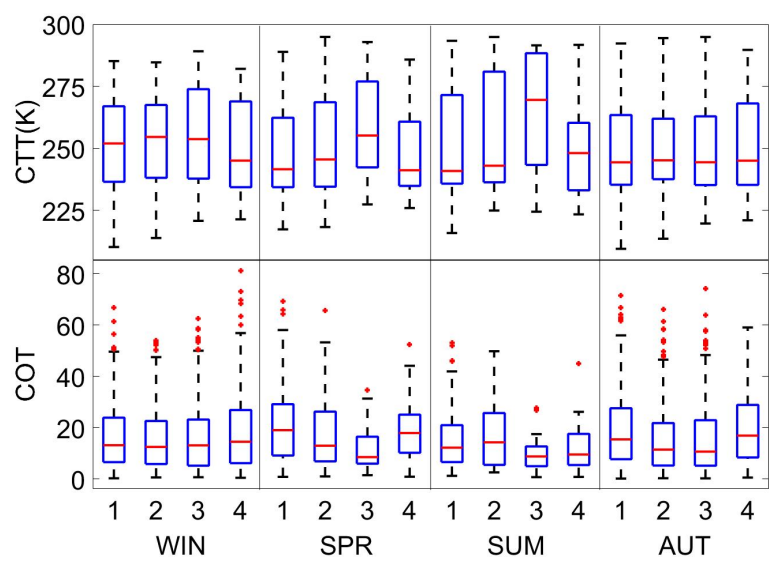

Figure 3. a) Cloud-top temperature $\left(\mathrm{CTT}_{H}\right)$ and; b) cloud optical thickness for high clouds $\left(\mathrm{COT}_{H}\right)$.

coincide with other studies (Calbó et al., 2008). The mean annual total cloud cover for the Iberian Peninsula is 52\%.

The annual averages of cloud cover show a latitudinal dependency with higher values $(53-61 \%)$ in the northern half of the Iberian Peninsula (regions 1 and 4) and lower values $(49-53 \%)$ in the southern part (regions 2 and 3 ). These estimations concur with the values reported by Calbó and Sánchez-Lorenzo (2009) using three different datasets, especially for the northern part of the Iberian Peninsula.
Nevertheless, our values in regions 2 and 3 are slightly larger.

\subsection{Cloud characteristics}

We carried out a seasonal analysis of the cloud characteristics directly derived by MODIS measurements: cloud optical thickness and cloud-top temperature. The 25 and 75 percentiles of the cloud optical thickness for low clouds $\left(\mathrm{COT}_{L}\right)$ ranges between 4 and 34, with annual averages around 16-19 (Fig. 2). For high clouds, the optical thickness $\left(\mathrm{COT}_{H}\right)$ is between 5 and 30 , and the annual mean is slightly lower, ranging from 12 to 17 (Fig. 3). Although the interval of variation is similar in both cases, the median values for high clouds are lower than for low clouds.

We observe no seasonal variation, but there is a

Table 2. Annual average of the cloud radiative effects for the Iberian Peninsula.

\begin{tabular}{ccc} 
& LOW CLOUDS & HIGH CLOUDS \\
\hline $\mathrm{CRE}_{L W}\left(W m^{-2}\right)$ & $16(10)$ & $73(14)$ \\
$\mathrm{CRE}_{S W}\left(W m^{-2}\right)$ & $-78(40)$ & $-84(35)$ \\
$\mathrm{CRE}_{N E T}\left(W m^{-2}\right)$ & $-62(40)$ & $-11(30)$ \\
\hline
\end{tabular}

regional one in COT (Fig. 2 and Fig. 3). In addition, region 1 has higher values (both $\mathrm{COT}_{L}$ and $\mathrm{COT}_{H}$ ), while region 3 has the lower ones except in summer $\left(\mathrm{COT}_{L}\right)$. This behaviour is related to the $20 \%$ difference in cloud cover of region 1 compared to region 3. The summer exception observed in region 3 may be a consequence of an increase in the aerosol concentration (Obregón et al., 2012). This higher aerosol concentration may favour the aerosol-cloud interactions decreasing the cloud droplet sizes and resulting in a higher cloud optical thickness (Nakajima et al., 2001; Kaufman et al., 2005).

On the other hand, the cloud-top temperature for high clouds $\left(\mathrm{CTT}_{H}\right)$ shows more spread than for low clouds (Fig. 3). At this latitude, low-cloud top height is generally around 3-4 $\mathrm{km}$ and the cloud-top temperature is limited by the lapse rate (Hahn et al., 2001). Therefore, the cloud-top temperature for low clouds $\left(\mathrm{CTT}_{L}\right)$ is largely influenced by the surface heating (Eitzen et al., 2008) and consequently $\mathrm{CTT}_{L}$ increases during summer, especially in region 3 . However, for high clouds, $\mathrm{CTT}_{H}$ is more stable during the year except for a great increase in summer in region 3 (Fig. $3)$. 


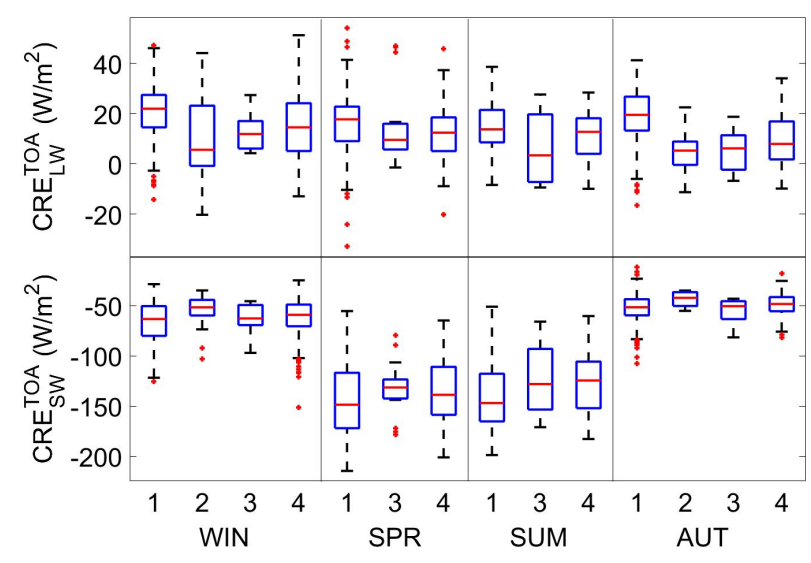

Figure 4. Cloud-radiative effect for low clouds in: a) longwave range $\left(\mathrm{CRE}_{L W}\right)$ and; b) shortwave $\left(\mathrm{CRE}_{S W}\right)$ range.

\subsection{Cloud-radiative effect (CRE)}

The 25 and 75 percentiles show that the CRE in the longwave range $\left(\mathrm{CRE}_{L W}\right)$ for low clouds varies between -10 and $30 \mathrm{Wm}^{-2}$, with the positive sign indicating warming. Again, we find no seasonal variation. but a regional one causing differences in the median values (Fig. 4). The data spread is different for the regions, being lower in region 3 that has lower cloudiness. For all seasons, the maximum $\mathrm{CRE}_{L W}$ appears in region 1, and the minimum in regions 2 and 3 , which generally show less cloudiness. The summer minimum in region 3 is associated with the maximum CTTL, since CTT is close to the surface temperature and the upwelling LW radiation is similar in cloud and in clear sky conditions, resulting in low $\mathrm{CRE}_{L W}$. The mean value obtained for the whole peninsula is $16 \mathrm{Wm}^{-2}$ (Table 2).

On the contrary, $\mathrm{CRE}$ in the shortwave range $\left(\mathrm{CRE}_{S W}\right)$ for low clouds exhibits a seasonal variation following the solar annual cycle. The maximum in absolute value appears in spring-summer for all the regions. The $\mathrm{CRE}_{S W}$ shifts from $-40 \mathrm{Wm}^{-2}$ in winter-autumn to $-170 \mathrm{Wm}^{-2}$ in spring-summer, when the solar radiation is higher and so is the cloud absorption and reflexion. Region 2 is not shown in spring and summer due to the lack of data. This does not mean that there are no low clouds but that their cover is under $80 \%$. For the entire Iberian Peninsula, low clouds produce a $\mathrm{CRE}_{S W}$ of $-78 \mathrm{Wm}^{-2}$ (Table 2).

For high clouds, the CRE in the longwave range $\left(\mathrm{CRE}_{L W}\right)$ is between $60 \mathrm{Wm}^{-2}$ and $100 \mathrm{Wm}^{-2}$, and thus larger than that for low clouds. This trend is caused by a difference between the cloud emission temperature and the Earth's surface. For low clouds, CTT is close to the surface temperature, leading to similar thermal emission reaching the top of the atmosphere, and thus low $\mathrm{CRE}_{L W}$ values. On the contrary, high clouds are cooler than the surface and they emit less longwave radiation. This leads to a net reduction of the thermal radiation on top of the atmosphere and to a significantly higher $\mathrm{CRE}_{L W}$. Its magnitude is fairly

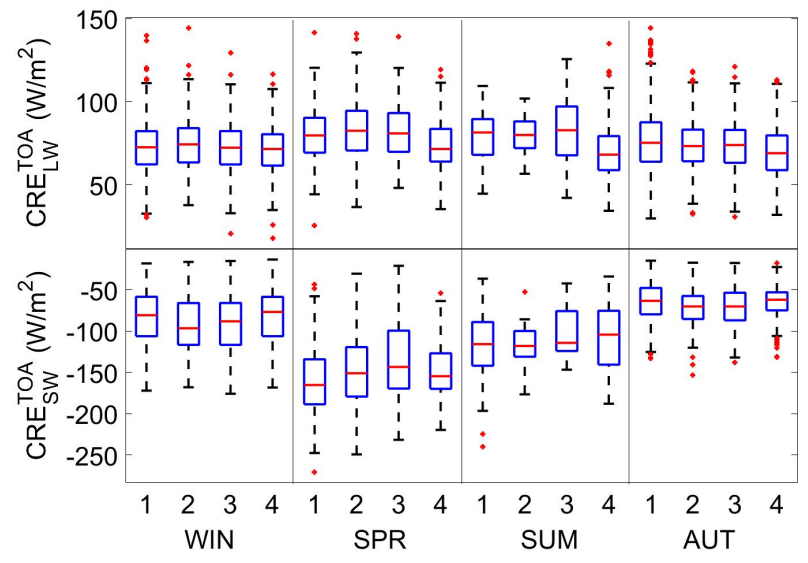

Figure 5. Cloud-radiative effect for high clouds in the: a) longwave range $\left(\mathrm{CRE}_{L W}\right)$ and; b) shortwave range $\left(\mathrm{CRE}_{S W}\right)$.

stable throughout the year for all regions except for a slight increase in spring and summer in regions 1,2 and 3 . The minimum $\mathrm{CRE}_{L W}$ is found in region 4 in summer. Considering that region 4 is the coldest on the Iberian Peninsula - the mean temperature of the warmest month being under $22{ }^{\circ} \mathrm{C}$ (AEMET, 2011) - the surface temperature is lower than in the other areas. Consequently, longwave radiation emitted is lower too, and thus the $\mathrm{CRE}_{L W}$ is smaller. For the whole Iberian Peninsula, the $\mathrm{CRE}_{L W}$ produced by high clouds is $73 \mathrm{Wm}^{-2}$. The $\mathrm{CRE}_{L W}$ is noticeably higher than that observed for low clouds because of the cloud height and the lower CTT, as has already been discussed.

The shortwave radiative effect $\left(\mathrm{CRE}_{S W}\right)$ is between -50 and $-190 \mathrm{Wm}^{-2}$ for high clouds with marked seasonal changes (Fig. 4). In spring, the $\mathrm{CRE}_{S W}$ absolute value increases but slightly decreases in summer. The reason is twofold: first, the solar irradiation is higher in spring and summer; second COT in summer is slightly below the spring value. In addition, there is a regional $\mathrm{CRE}_{S W}$ variation particularly in spring due to the great variability in the atmospheric conditions. Region 1 exhibits the more intense $\mathrm{CRE}_{S W}$ of this season. The mean value of the $\mathrm{CRE}_{S W}$ for the entire Iberian Peninsula is $-84 \mathrm{Wm}^{-2}$ (Table 2), quite similar to the $\mathrm{CRE}_{S W}$ observed for low clouds.

The net radiative effect is the sum of the short- and longwave components. Its value for low clouds increases seasonally from $-20 \mathrm{Wm}^{-2}$ (in autumn) to $-150 \mathrm{Wm}^{-2}$ (in spring and summer) with little difference between the climatic regions (see Fig. 6). On the other hand, the net radiative effect for high clouds ranges between $10 \mathrm{Wm}^{-2}$ and $-110 \mathrm{Wm}^{-2}$ (see Fig. 7). The positive effect in autumn is remarkable, when the longwave effect exceeds the shortwave one. This trend was also found by Chen et al. (2000). The $\mathrm{CRE}_{N E T}$ is $-78 \mathrm{Wm}^{-2}$ for low clouds and $-11 \mathrm{Wm}^{-2}$ for high clouds (Table 2). This marked difference comes from the $\mathrm{CRE}_{L W}$, which is directly influenced by the cloud height. 


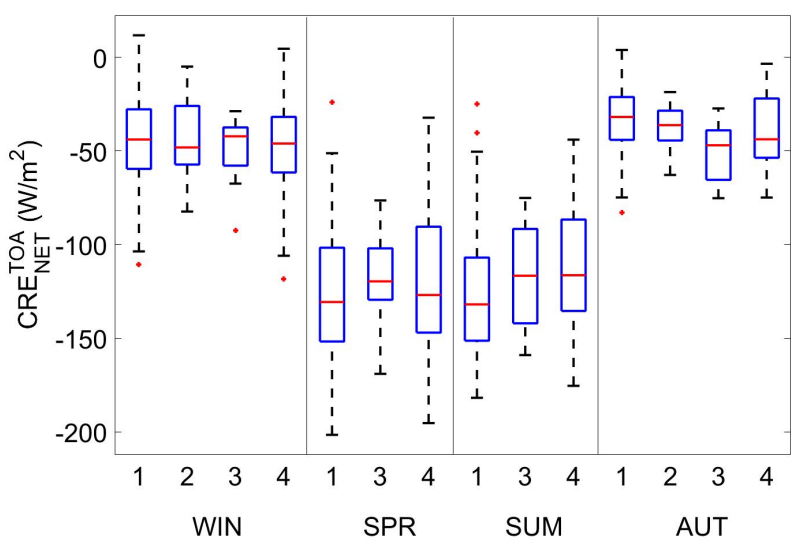

Figure 6. Net cloud-radiative effect for low clouds $\left(\mathrm{CRE}_{N E T}\right)$.

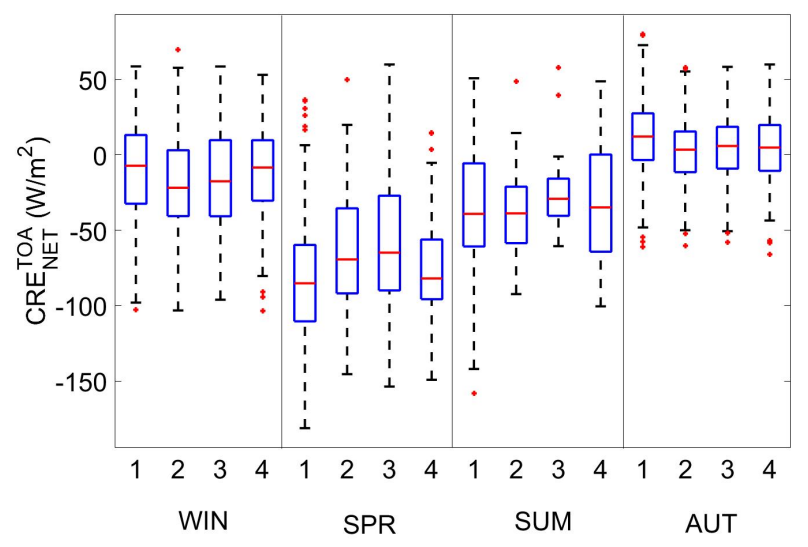

Figure 7. Net cloud-radiative effect for high clouds $\left(\mathrm{CRE}_{N E T}\right)$.

\section{Conclusions}

This paper presents a seasonal cloud analysis of the four climatic regions into which the Iberian Peninsula has been divided. Long- and shortwave effect on top of the atmosphere, cloud optical thickness and cloud-top temperature have been discussed. Our work is limited to 12 years of satellite data and cannot be considered as a climatic study. In addition, only overcast conditions presenting a single cloud type were analysed. However, differences between seasons and regions have been highlighted.

We notice differences in optical thickness between regions, being more marked for low clouds. However, both for high and low clouds, the median is between 10 and 20. On the other hand, radiative effect changes seasonally. In terms of effect, spring and summer values are similar. The effect in winter and autumn is also close, though different from the values for spring and summer. Cloud height greatly affects the $\mathrm{CRE}_{L W}$ depending on the magnitude of the temperature difference between clouds and ground.

Acknowledgements. This piece of research was jointly financed by the Spanish Ministry of Economy and Competitiveness
(MINECO) and the European Regional Development Fund (FEDER) through Projects CGL2015-64785R and CGL2015$70432 \mathrm{R}$ and by the Valencia Autonomous Government through Project PROMETEUII/2014/058. The authors would like to thank the Atmospheric Science Data Center in the NASA Langley Research Center for the CERES data and the NASA Goddard Space Flight Center for the MODIS data.

\section{References}

AEMET, 2011: Agencia Estatal de Meteorologia (España), Instituto de Meteorología (Portugal), Iberian Climatic Atlas., isbn: 97884-7837-079-5 (in Spanish).

Ahrens, D. C., 2009: Meteorology Today, an introduction to Weather, Climate, and the Environment, Brooks/Cole, Belmont, CA (USA).

Boers, R., de Haij, M., Wauben, W., Baltink, H., van Ulft, L., Savenije, M., and Long, C., 2010: Optimized fractional cloudiness determination from five ground-based remote sensing techniques, J. Geophys. Research, 115, 1-16.

Calbó, J. and Sabburg, J., 2008: Feature extraction from wholesky ground-based images for cloud-type recognition, J. Atmos. Ocean. Technol., 25, 3-14, doi:10.1175/2007JTECHA959.1.

Calbó, J. and Sánchez-Lorenzo, A., 2008: Cloudiness climatology in the Iberian Peninsula from three gridded datasets (ISCCP, CRU TS 2.1, ERA-40), Theoretical and Applied Climatology, pp. $105-115$.

Calbó, J., Pages, D., and Gonzalez, J., 2005: Empirical studies of cloud effects on UV radiation: a review, Review Geophysics, 43, $1-28$.

Calbó, J., A., Sánchez-Lorenzo, Martín-Vide, J., and Brunetti, M., 2008: Aspectos climatologicos y evolución temporal de la nubosidad en la Península Ibérica (1961-2004), Cambio climático regional y sus impactos, A, 57-67.

Cess, R. D., Potter, G. L., Blanchet, J. P., Boer, G. J., Ghan, S. J., Kiehl, J. T., Treut, H. L., Li, Z.-X., Liang, X.-Z., Mitchell, J. F. B., Morcrette, J.-J., Randall, D. A., Riches, M. R., Roeckner, E., Slingo, U. A., Taylor, K. E., Washington, W. M., Wetherald, R. T., and Yagai., I., 1989: Interpretation of Cloud-Climate Feedback as Produced by 14 Atmospheric General Circulation Models, Science, 245, 513.

Chen, T., Rossow, W., and Zhang., Y., 2000: Radiative effects of cloud-type variations, Journal of Climate, 13, 264-286.

Chýlek, P. and Wong, J., 1989: Cloud radiative forcing ratio - an analytical model, Tellus A, 50, 259-264.

Doelling, D. R., Loeb, N. G., Keyes, D. F., Nordeen, M. L., Morstad, D., Nguyen, C., Wielicki, B. A., Young, D. F., and Sun., M., 2013: Geostationary enhanced temporal interpolation for CERES flux products, Journal of Atmospheric and Oceanic Technology, 30, 1072-1090.

Dong, X., Minnis, P., Xi, B., Sun-Mack, S., and Chen, Y., 2008: Comparison of CERES-MODIS stratus cloud properties with ground-based measurements at the DOE ARM Southern Great Plains site, J. Geophys. Res., 113, doi:10.1029/2007JD008438.

Dürr, B. and Philipona, R., 2004: Automatic cloud amount detection by surface longwave downward radiation measurements, J. Geophys. Res., 109, doi:10.1029/2003JD004182. 
Eitzen, Z. A., Xu, K., and Wong, T., 2008: Statistical analyses of satellite cloud object data from CERES. Part V: Relationships between physical properties of marine boundary layer clouds, Journal of Climate, 21, 6668-6688.

Hahn, C. J., Rossow, W. B., and Warren, S. G., 2001: ISCCP cloud properties associated with standard cloud types identified in individual surface observations, Journal of Climate, 14, 1128.

Kaufman, Y. J., Koren, I., Remer, L., Rosenfeld, D., and Rudich, Y., 2005: The effect of smoke, dust, and pollution aerosol on shallow cloud development over the Atlantic Ocean, Proceedings of the National Academy of Sciences of the United States of America, 102, $11207-11212$.

Lin, X., Randall, D., and Fowler, L., 2000: Diurnal Variability of the Hydrologic Cycle and Radiative Fluxes: Comparisons between Observations and a GCM, J. Climate, 13, 4159-4179.

Long, C. N. and Ackerman, T. P., 2000: Identification of clear skies from broadband pyranometer measurements and calculation of downwelling shortwave cloud effects, Geophys. Res. Atmos., 105, 15 609-15 626, doi:10.1029/2000JD900077.

Long, C. N., Slater, D., and Tooman, T., 2001: Total sky imager model 880 status and testing results, ARM TR-006, pp. 1-17.

Long, C. N., Ackerman, T., Gaustad, K., and Cole, J., 2006: Estimation of fractional sky cover from broadband shortwave radiometer measurements, J. Geophys. Res. Atmos., 111, doi: 10.1029/2005JD006475.

Lyamani, H., Valenzuela, A., Perez-Ramirez, D., Toledano, C., Granados-Muñoz, M., F.J.Olmo, and Alados-Arboledas, L., 2015: Aerosol properties over the western Mediterranean basin: temporal and spatial variability, Atmospheric Chemistry and Physics, 15, 2473-2486.

Martínez-Lozano, J., Utrillas, M., Núñez, J., Tamayo, J., Marín, M., Esteve, A., Cañada, J., and Moreno, J., 2011: Ozone mini-holes over Valencia (Spain) and their influence on the UV erythemal radiation, International Journal of Climatology, 31, 1554-1566, doi:10.1002/joc. 2173 .

Martucci, G., Milroy, C., and O'Dowd, C., 2010: Detection of Cloud-Base Height Using Jenoptik CHM15K and Vaisala CL31 Ceilometers, J. Atmos. Ocean. Technol., 27, 305-318, doi:10. 1175/2009JTECHA1326.1.

McCoy, D. T., Hartmannand, D., and Grosvenor, D., 2014: Observed southern ocean cloud properties and shortwave reflection. Part II: Phase changes and low cloud feedbacks, Journal of Climate, 27, 8858-8868.

Min, Q., Joseph, E., Lin, Y., Min, L., Yin, B., Daum, P., Kleinman, L., and J. Wang, Y.-N. L., 2012: Comparison of MODIS cloud microphysical properties with in-situ measurements over the Southeast Pacific, Atmos.Chem.Phys., 12, 11 261-11 273.

Minnis, P. S., Sun-Mack, Young, D., Heck, P. W., Garber, D., Chen, Y., Spangenberg, D., Arduini, R., Trepte, Q., Smith, W., Ayers, J., Gibson, S., Miller, W., Hong, G., Chakrapani, V., Takano, Y., Liou, K. N., Xie, Y., and Yang, P., 2011: CERES Edition2 Cloud Property Retrievals Using TRMM VIRS and Terra and Aqua MODIS Data -Part I: Algorithms, IEEE Transactions on Geoscience and Remote Sensing, 49, 4374-4400.

Morland, J. and Matzler, C., 2007: Spatial interpolation of GPS integrated water vapour measurements made in the Swiss Alps, Meteorological Applications, 14, 15-26.

Morris, V., 2004: Total Sky Imager (TSI) Handbook, US Department of Energy.
Nakajima, T. and King, M. D., 1990: Determination of the optical thickness and effective particle radius of clouds from reflected solar radiation measurements. Part I: Theory, J. Atmos. Sci., 47, 1878-1893, doi:10.1175/1520-0469.

Nakajima, T., Higurashi, A., Kawamoto, K., and Penner, J., 2011: A possible correlation between satellite-derived cloud and aerosol microphysical parameters, Geophysical Research Letters, 28, 1171-1174.

Oznovitch, I., Yee, R., Schiffler, A., McEwen, D., and Sofko, G., 1994: The all-sky camera revitalized, Appl. Optics, 33, 7141-7150.

Platnick, S., King, M., Ackerman, S., Menzel, W., Baum, B., Riédi, J., and Frey, R., 2003: The MODIS cloud products: algorithms and examples from Terra, IEEE Transactions on Geoscience and Remote Sensing, 41, 459-473.

Ramanathan, V., Cess, R., Harrison, E., Minnis, P., Barkstrom, B., Ahmad, E., and Hartmann, D., 1989: Cloud-radiative forcing and climate: Results from the Earth Radiation Budget Experiment, Science, 243, 57-63.

Roebeling, R., Baum, B. A., Bennartz, R., Hamann, U., Heidinger, A., Thoss, A., and Walther, A., 2013: Evaluating and improving cloud parameter retrievals, Bulletin of the American Meteorological Society, 94, ES41-ES44.

Rossow, W. B. and A., S. R., 1991: ISCCP cloud data products, Bulletin of the American Meteorological Society, 72, 2-20.

Ruffieux, D., Nash, J., Jeannet, P., and Agnew, J., 2006: The COST 720 temperature, humidity, and cloud profiling campaign, Meteorologische Zeitschrift, 5, 5-10.

Sanchez-Lorenzo, A., Calbó, J., and Wild., M., 2012: Increasing cloud cover in the 20 th century: review and new findings in Spain, Clim. Past, 8, 1199-1212, doi:10.5194/cp-8-1199-2012.

Shields, J., Karr, M., Tooman, T., Sowle, D., and Moore, S., 1998: TheWhole Sky Imager-A Year of Progress, Eighth Atmospheric Radiation Measurement (ARM) Science Team Meeting, pp. 2327.

Solomon, S., Qin, D., Manning, M., Chen, Z., Marquis, M., Averyt, K., Tignor, M., and H.L.Miller, 2007: Contribution of Working Group I to the Fourth Assessment Report of the Intergovernmental Panel on Climate Change, Cambridge University Press, p. 996.

Warren, S. G. and C.J., H., 2003: Clouds: climatology, Encyclopedia of Atmospheric Sciences, 2, 476-483.

Wielicki, B. A., Barksotrm, B., Harrison, E., III, R. L., Smith, G., and Cooper, J., 1996: Clouds and the Earth's Radiant Energy System (CERES): An Earth Observing System Experiment, Bulletin American Meteorological Society, 77, 853-868.

Xu, K. M., Wong, T., Wielicki, B. A., Parker, L., and Eitzen, Z. A., 2005: Statistical analyses of satellite cloud object data from CERES. Part I: Methodology and preliminary results of the 1998 El Niño/2000 La Niña, J. Climate, 18, 2497-2514, doi: 10.1175/JCLI3418.1. 